\title{
PHAETHON: Software for Analysis of Shear-Critical Reinforced Concrete Columns
}

\author{
Konstantinos G. Megalooikonomou ${ }^{1}$ \\ ${ }^{1}$ Department of Civil \& Environmental Engineering, University of Cyprus, Nicosia, Cyprus \\ Correspondence: Konstantinos G. Megalooikonomou, Department of Civil \& Environmental Engineering, \\ School of Engineering, University of Cyprus, 75 Kallipoleos Street, P.O. Box 20537,1678 Nicosia, Cyprus, Tel: \\ 357-2289-2221. Fax: 357-2289-5080. E-mail: kmegal01@ucy.ac.cy
}

$\begin{array}{ll}\text { Received: January 11, } 2018 & \text { Accepted: January } 29,2018 \quad \text { Online Published: February 7, } 2018 \\ \text { doi:10.5539/mas.v12n3p1 } & \text { URL: https://doi.org/10.5539/mas.v12n3p1 }\end{array}$

The research is financed by Alexander S. Onassis Public Benefit Foundation.

\begin{abstract}
Earthquake collapse of substandard reinforced concrete (RC) buildings, designed and constructed before the development of modern seismic design Codes, has triggered intense efforts by the scientific community for accurate assessment of this building stock. Most of the proposed procedures for the prediction of building strength and deformation indices were validated by assembling databases of RC column specimens tested under axial load and reversed cyclic lateral drift histories. Usually a column structural behavior is assessed by considering all involving mechanisms of behavior, namely flexure with or without the presence of axial load, shear and anchorage. In the present paper a force-based fiber beam/column element was developed accounting for shear and tension stiffening effects in order to provide an analytical test-bed for simulation of experimental cases such as the lightly reinforced columns forced to collapse. Their peculiar characteristics are the outcome of the shear - flexure interaction mechanism modeled here based on the Modified Compression Field Theory (MCFT) and the significant contribution of the tensile reinforcement pullout from its anchorage to the total column's lateral drift. These features are embedded in this first-proposed stand-alone Windows program named "Phaethon" -with user's interface written in $\mathrm{C}++$ programming language code- aiming to facilitate engineers in executing analyses both for rectangular and circular substandard RC columns.
\end{abstract}

Keywords: shear-critical columns, MCFT, anchorage pullout, fiber beam/column element, capacity curve

\section{Introduction}

Most of the state-of-the-art on seismic design and assessment procedures proposed recently for common engineering practice require some kind of nonlinear analysis either static or dynamic. These nonlinear analyses are mostly carried out using frame elements with different levels of approximation. Two main approaches are usually used, classified as lumped-plasticity and distributed-inelasticity models. The limitation of concentrated plasticity elements is that inelastic deformations take place at predetermined locations in the ends of the element. Another, in many respects more serious limitation, is the fact that concentrated plasticity elements require calibration of their parameters against the response of an actual or ideal frame element under idealized loading conditions. This is necessary, because the response of concentrated plasticity elements derives from the moment-rotation relation of their components. In an actual frame element the end moment-rotation relation results from the integration of the section response. This can be achieved directly with elements of distributed inelasticity (Filippou \& Fenves 2004). For the latter approach, the so-called fiber beam elements (Figure 1) provide results that seem to be particularly appropriate for studying the seismic behavior of RC structures: moment-axial force (M-N) coupling is readily taken into account as well as the interaction between concrete and steel in the section. Several fiber beam-column elements have been developed with good capability of reproducing axial force and flexure effects. On the other hand, the coupling between the effects of normal and shear forces is not straightforward and hence only few modeling strategies have accounted for and implemented it up to now (Ceresa et al., 2007).

A common theory, appropriate for analysis of beam-column elements, is the Euler-Bernoulli approach. The 
fundamental assumption of this theory is that cross-sections remain plain and normal to the deformed longitudinal axis. The engineering beam theory reproduces the response of a beam under combined axial forces and bending moments, while shear forces are recovered from static equilibrium; the effects of shear on beam's deformation are neglected. When effects of tangential stresses are important for the element deformation (i.e. in a beam-columns joint or in the column/wall plastic hinge length), more refined theories like as Timoshenko beam theory may be used.

In the development of a nonlinear frame element, two main approaches have been used, namely the displacement-based (stiffness) approach and the force-based (flexibility) approach. A flexibility-based frame element gives the exact solutions for non-linear analysis of frame structure, using force interpolation functions that strictly satisfy element equilibrium, and impose the compatibility conditions. Accordingly, this approach allows the overcoming of some limitations of the stiffness approach. In particular, the nonlinear analysis becomes independent of the displacement approximation, it requires fewer elements for the representation of the non-linear behavior and, above all, in the case of a Timoshenko element or exact-beam theory-element, it avoids the well-known shear-locking problem (sharp increase in the element stiffness that results in much less deformations for the element than expected) (Hughes, 2000).

One of the modeling strategies in order to incorporate the beam theory that includes shear into the fiber approach is related to the idea of adopting suitable constitutive relationships. In this category belong fiber beam-column elements using smeared cracking models. According to this approach, cracked concrete is simulated as a continuous medium with anisotropic characteristics. In general, these models are referred as "smeared cracking approaches" since cracking is modeled as a distributed effect with directionality. These approaches are particularly suitable for sectional analysis.

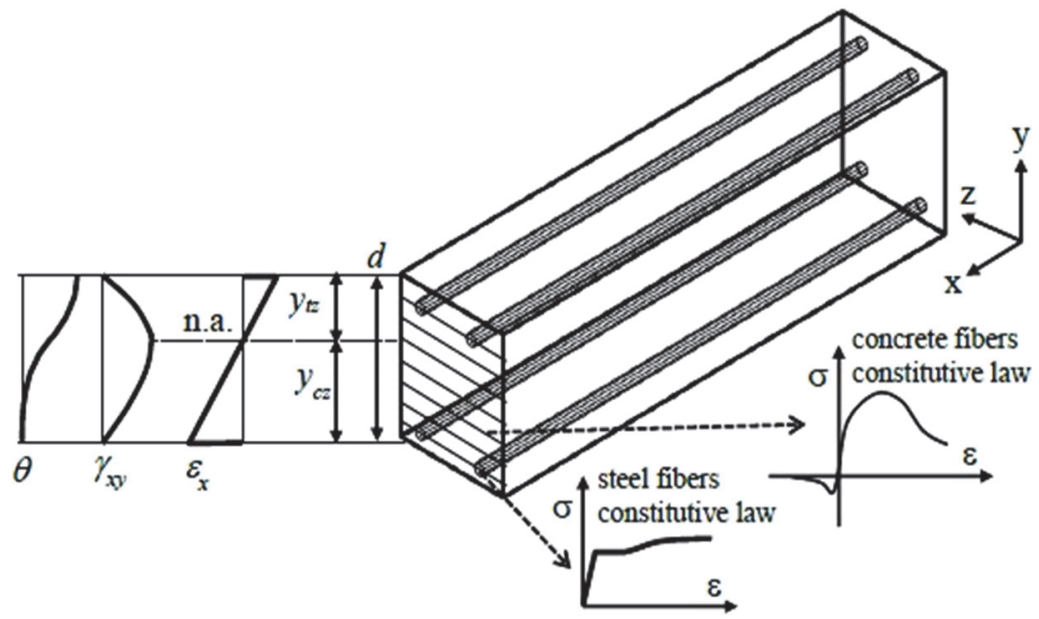

Figure 1. Fiber Element Scheme - definitions

\section{RC Sectional Model Based on MCFT}

Since the end of seventies considerable amount of experimental and analytical research has been conducted with the aim of developing analytical procedures capable of estimating the load-deformation response of reinforced concrete elements loaded in shear (Ceresa et al., 2008). At the University of Toronto, Collins developed a procedure called the compression field theory (CFT) in 1978 (Collins, 1978). In 1981, a competition was held to predict the load-deformation response of four reinforced concrete panels tested at the University of Toronto (Collins et al., 1985), where leading researchers from around the world entered predictions based on various constitutive approaches. The results indicated a poor state-of-the-art in analytical modeling of reinforced concrete structures. Generally, the models were not able to adequately estimate the ultimate strength, the failure mode or the load-deformation response of the panels. Most of the entrants used constitutive theories developed from tests conducted on plain concrete specimens. Conditions in the specimens are not representative of actual RC structures. The interaction between the concrete and steel strongly influences the response of reinforced concrete structures. In an effort to determine more realistic relationships for cracked reinforced concrete, Vecchio and Collins (1982) tested a series of RC panels. From these tests, the modified compression field theory (MCFT) (Vecchio \& Collins, 1986) was calibrated by including stress-strain relationships for cracked reinforced concrete under plane stress conditions. 
A RC element is homogenized and is treated as anisotropic elastic material shown in Figure 2. Consider an elementary panel under constant plane stress, of uniform thickness, containing an orthogonal grid of well distributed reinforcement. Loads acting on the element's edge planes are assumed to consist of uniform membrane stresses, i.e., axial stresses $\mathrm{n}_{\mathrm{x}}, \mathrm{n}_{\mathrm{y}}$ and uniform shear stresses $\tau_{\mathrm{xy}}$. The deformed shape is defined by the strain tensor for plane stresses:

$$
\left[\begin{array}{ccc}
\varepsilon_{x} & \gamma_{x y} / 2 & 0 \\
\gamma_{x y} / 2 & \varepsilon_{y} & 0 \\
0 & 0 & \varepsilon_{z}
\end{array}\right]
$$
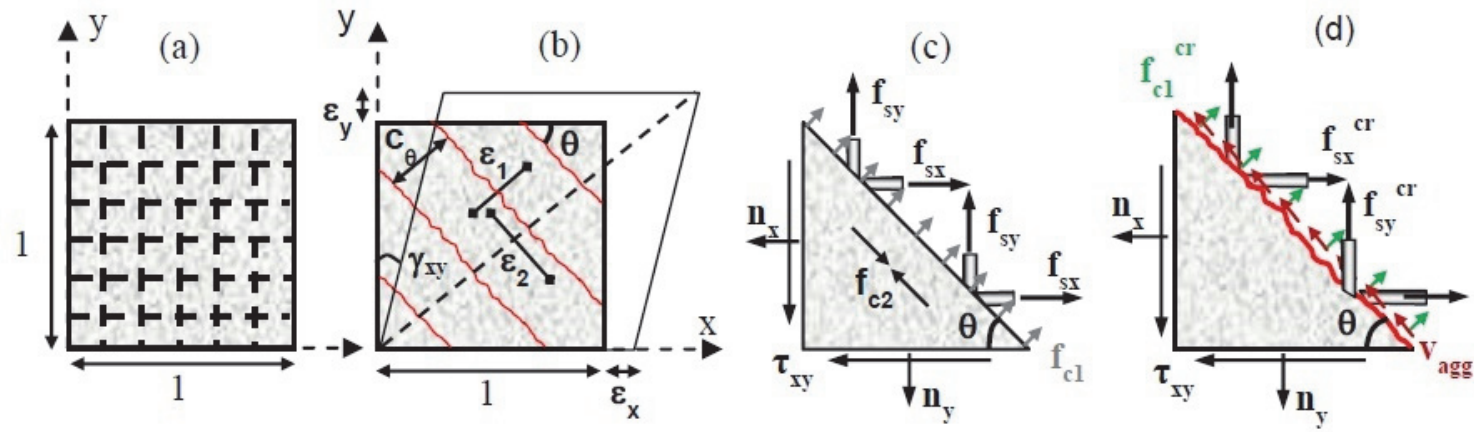

Figure 2. a) RC smeared-cracking membrane element, b) average strains $\left(C_{\theta}\right.$ :spacing of cracks inlined at $\left.\left.\theta\right) \mathrm{c}\right)$ average stresses and d) local stresses at a crack ( $v_{\text {agg }}$ :shear stress on crack surface)

The MCFT utilizes the following assumptions:

- The reinforcement is averaged or smeared throughout the element, i.e. it applies only to well-detailed members.

- The stresses applied to the element are uniform along edges.

- The total stress state is a function of the total strain state.

- The reinforcement is perfectly bonded to concrete, so that relative displacement due to bond slip between reinforcement and concrete is ignored.

- The shear stress is negligible in reinforcement.

- The principal stresses and principal strain axes are coincident; as consequence, no deviation between the two is allowed.

- The constitutive relationships for concrete and reinforcement are independent.

- The cracks are smeared and allowed to rotate.

The theory comprises three sets of relationships: compatibility relationships between concrete and reinforcement average strains, equilibrium relationships between externally applied loads and average stresses in the concrete and reinforcement; and uniaxial constitutive relationships for cracked concrete along the principal directions and for reinforcement. The constitutive relationships for cracked concrete result from tests of reinforced concrete panels using a purpose-built Panel Element Tester at the University of Toronto. As such, the formulation of the MCFT calibrated with the specific tests conducted in the panel tester, incorporates realistic constitutive models for concrete based on experimentally observed phenomena. While cracks are smeared and the relationships are formulated in terms of average stresses and strains, a critical aspect of the MCFT is the consideration of the local strain and stress conditions at cracks (Figure 2d).

\subsection{Constitutive Model based on MCFT for a Fiber RC Beam}

In order to determine the normal and the shear stresses for the i-th fiber / layer $\left(\sigma_{x}{ }^{i}, \tau_{x y}{ }^{i}\right)$ of a fiber section of a RC beam (Vecchio \& Collins, 1988) a bi-axial fiber constitutive model is developed according to the Modified Compression Field Theory (MCFT) (Table 1). For the section state determination the following assumptions were made: the longitudinal $\varepsilon_{x}$ and shear $\gamma_{x y}$ strains are known for each fiber, according to plane section assumption and to a parabolic shear strain distribution along the height of the section with the maximum value 
$\gamma_{x y \text { max }}$ located on the neutral axis $y_{n a}$ (Equation 2, two half-parabola with the same maximum are met to the point of neutral axis with different starting point, extreme tensile and extreme compressive fiber respectively).

$$
\gamma_{x y}(y)=\gamma_{x y \cdot \max } \cdot\left[2\left(\frac{y}{y_{n a}}\right)-\left(\frac{y}{y_{n a}}\right)^{2}\right]
$$

The transversal concrete stress $f_{c y}$ was determined for each fiber from equilibrium conditions (zero normal stress $n_{y}$ was assumed). The constitutive law is based on an iterative procedure (Figure 3) where in order to accelerate the convergence of the algorithm to the right angle $\theta$, the initial guess value of the procedure for the angle of inclination of principal stresses / strains (angle of principal axis 2 with respect to $x$-axis) is determined according to the following equation:

$$
\begin{gathered}
\theta(y)=\frac{\pi}{4} \cdot\left(\frac{y}{y_{c z}}\right)^{3}, 0<y \leq y_{c z} \\
\theta(y)=\frac{\pi}{4}+\frac{\pi}{4} \cdot\left[2\left(\frac{y-y_{c z}}{y_{t z}}\right)-\left(\frac{y-y_{c z}}{y_{t z}}\right)^{2}\right], \quad y_{c z}<y \leq d
\end{gathered}
$$

where $y$ is the location of the concrete layer/fiber $(y$ : start measuring from the extreme compressive fiber, Figure 1), $y_{c z}$ is the depth of the compression zone, $y_{t z}$ is the depth of the tension zone and $d$ is the total depth of the section (i.e., $y_{c z}+y_{t z}=d$, Figure 1). Figure 4 depicts the angle shape function along the height of the section according to the above equation $\left(d=457 \mathrm{~mm}, y_{c z}=280 \mathrm{~mm}\right.$ similar to Specimen 1 (Sezen \& Moehle, 2006)). The solution of the iterative procedure is reached by applying the Regula Falsi root finding numerical solution (Chabert, 1999).

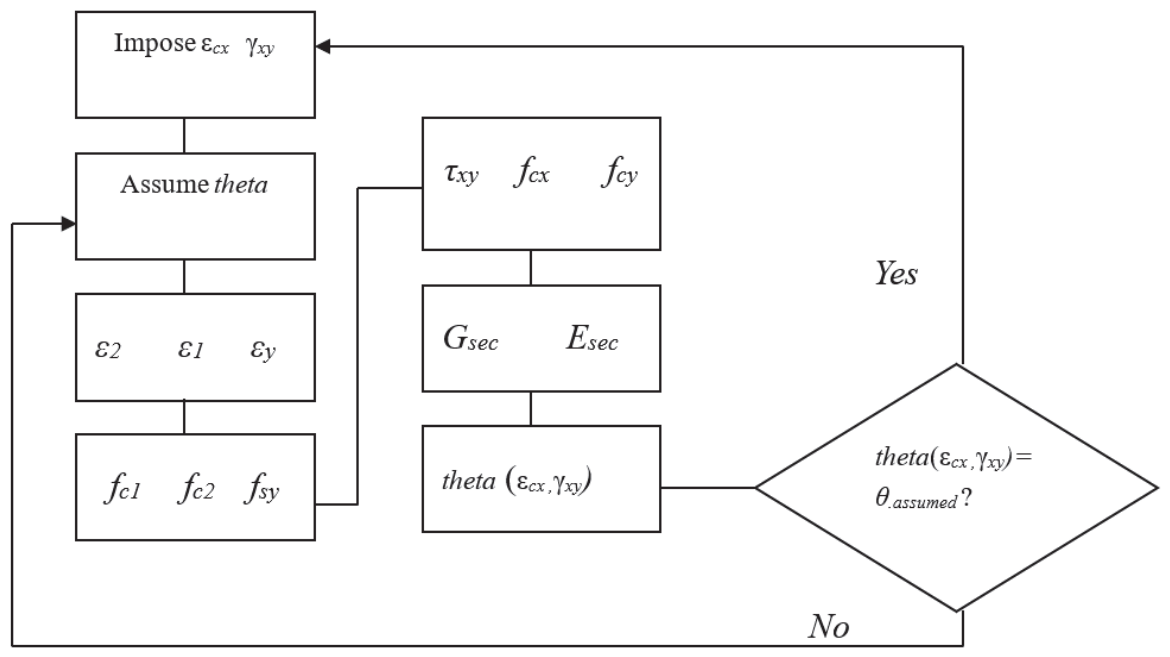

Figure 3. Iterative procedure for each fiber/layer of the section according to MCFT

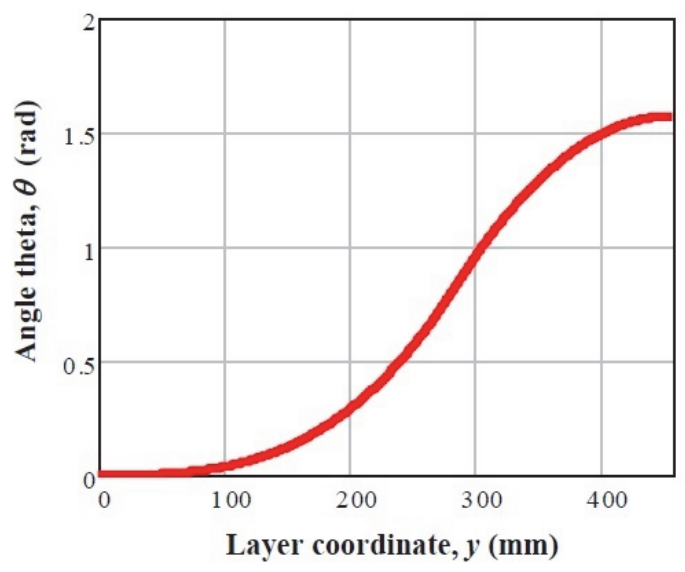

Figure 4. Shape function for angle theta $(\theta)$ of inclination of principal stresses/strains 
Table 1. Equations embodied in the iterative procedure (Vecchio \& Collins, 1988).

$$
\begin{aligned}
& \varepsilon_{x}=\varepsilon_{c x}, \varepsilon_{1}=\varepsilon_{x}+\frac{\gamma_{x y} \cdot \tan (\pi / 2-\theta)}{2}, \varepsilon_{y}=\varepsilon_{1}-\frac{\gamma_{x y}}{2 \cdot \tan \left(\pi / 2^{-\theta}\right)}, \varepsilon_{2}=\varepsilon_{x}+\varepsilon_{y}-\varepsilon_{1} \\
& f_{c 1}=E_{c} \cdot \varepsilon_{1} \text { for } 0<\varepsilon_{1} \leq \varepsilon_{c r}, \quad f_{c 1}=\frac{f_{c r}}{1+\sqrt{200 \varepsilon_{1}}} \text { for } \varepsilon_{c r}<\varepsilon_{1} \leq \varepsilon_{y x}, \\
& f_{c 2}=f_{c 2 \max } \cdot\left[2\left(\frac{\varepsilon_{2}}{\varepsilon_{c}^{\prime}}\right)-\left(\frac{\varepsilon_{2}}{\varepsilon_{c}^{\prime}}\right)^{2}\right], \frac{f_{c 2 \max }}{f_{c}^{\prime}}=\frac{1}{0.8-0.34 \varepsilon_{1} / \varepsilon_{c}^{\prime}} \leq 1.0, f_{s y}=E_{s y} \varepsilon_{y} \leq f_{y y} \\
& f_{c y}=-\rho_{y} \cdot f_{s y}, \tau_{x y}=\frac{f_{c y}-f_{c 2}}{\tan \left(\pi / 2^{-\theta}\right)}, f_{c x}=f_{c 1}-\tau_{x y} \cdot \tan (\pi / 2-\theta), G_{s e c}=\frac{\tau_{x y}}{\gamma_{x y}}, \quad E_{s e c}=\frac{f_{c x}}{\varepsilon_{x}}, \\
& \operatorname{theta}\left(\varepsilon_{c x}, \gamma_{x y}\right)=\tan ^{-1} \frac{f_{c 1}-f_{c y}}{\tau_{x y}}
\end{aligned}
$$

$f_{c}^{\prime}=$ Concrete Cylinder Compressive Strength (MPa), $\varepsilon_{c}^{\prime}=$ Strain at Concrete Cylinder Compressive Strength, $E_{c}=$ Concrete Elastic Modulus (MPa), $f_{c r}=$ Tensile Concrete Strength (MPa), $\varepsilon_{c r}=$ Strain at Tensile Concrete Strength, $\varepsilon_{y x}=$ Yielding Strain of Longitudinal Reinforcement, $E_{s y}=$ Elastic Modulus of Stirrups (MPa), $f_{y y}=$ Yielding Strength of Stirrups (MPa), $\rho_{y}=$ Stirrups Reinforcement Ratio.

\subsection{Sectional Model}

Figure 5 depicts a beam element with its degrees of freedom and its displacement/ forces in global, local and basic systems of reference. The term "basic" is referred to the system of reference where the rigid body motion of the beam is extracted. Considering now the virtual work principle for the beam element of Figure 5, the Equation 4 can be derived. The external work is done by the end forces $(p)$ on the corresponding displacements $(u)$, whereas the internal work is done by the basic forces $(q)$ on the corresponding deformations $(v)$.

$$
\delta u^{T} p=\delta v^{T} q
$$

The internal work of Equation 4 can be derived from the integral of the stress product with the corresponding virtual strains over the element volume $V$. In many applications of nonlinear structural analysis, the internal work is limited to the internal work of normal stress $\sigma_{x}$ and shear stress $\tau$ on the axial strain $\varepsilon_{x}$ and shear strain $\gamma$ respectively:

$$
\delta v^{T} q=\int \delta \varepsilon^{T} \sigma d V=\int\left(\delta \varepsilon_{x} \sigma_{x}+\delta \gamma \tau\right) d V
$$
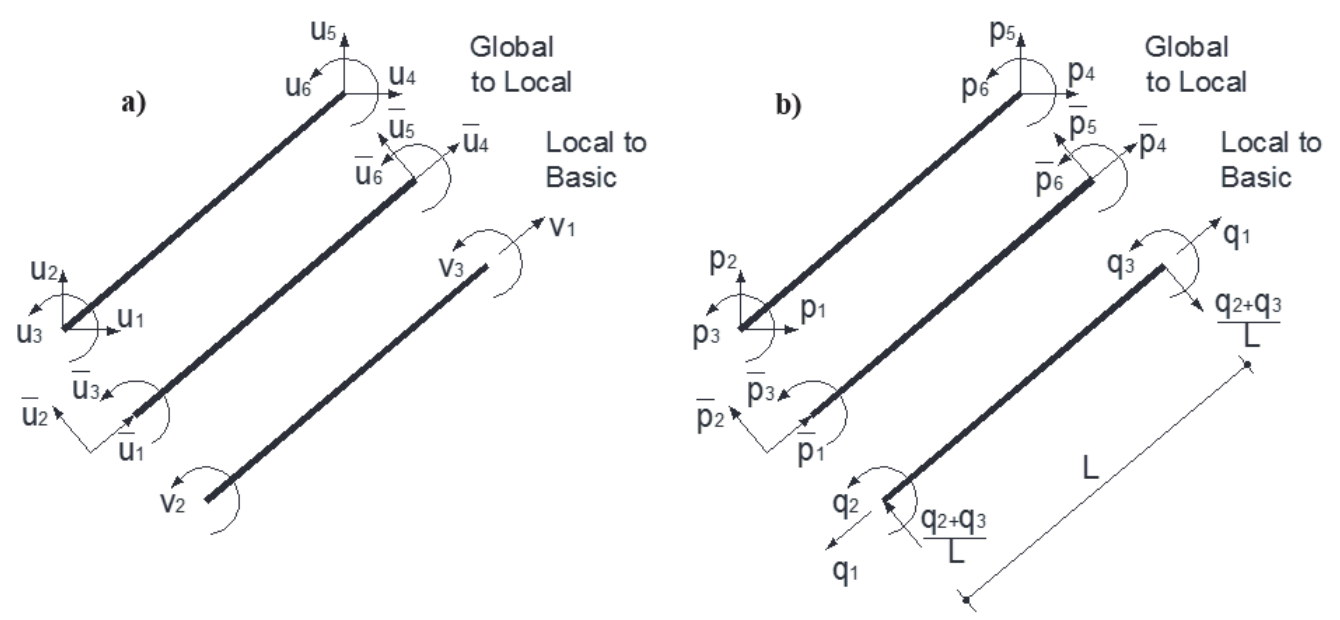

Figure 5. Beam a) displacements and b) forces in global, local and basic reference systems 
The strain and stress are functions of the position along the element longitudinal axis $x$ and the position within the cross section specified in local coordinates $y$ (with respect to the height) and $z$ (with respect to the width).

Equation 5 can be rewritten by substituting the integral over the element volume as integration over the section area $A$ at a location $x$ followed by integration over the element length:

$$
\delta v^{T} q=\int\left(\delta \varepsilon_{x} \sigma_{x}+\delta \gamma \tau\right) d V=\int\left[\int\left(\delta \varepsilon_{x} \sigma_{x}+\delta \gamma \tau\right) d A\right] d x
$$

The strains at a fiber/layer point of the beam cross section ( $2 d$ case) are related to the section deformations as follows (Ceresa et al, 2008):

$$
\begin{gathered}
\varepsilon_{x}(x)=\varepsilon_{0}-y_{\varepsilon} \cdot \varphi(x) \\
\gamma_{x y}(x)=\gamma_{x y \text { max }}
\end{gathered}
$$

Where $\varepsilon_{0}$ is the axial deformation at the center of the coordinate system of the section (center of mass) and $y_{\varepsilon}$ counts also from this center, $\varphi(x)$ is the curvature of the cross-section and $\gamma_{x y \text { max }}$ is the maximum value of shear strain located on the neutral axis. Therefore the strains at a material point $m$ of the section can be expressed in matrix form as follows:

$$
\begin{gathered}
\varepsilon\left(x, y_{\varepsilon}\right)=\left\{\begin{array}{c}
\varepsilon_{x} \\
\gamma_{x y}
\end{array}\right\}=\left[\begin{array}{ccc}
1 & -y_{\varepsilon} & 0 \\
0 & 0 & 1
\end{array}\right] \cdot\left\{\begin{array}{c}
\varepsilon_{0} \\
\varphi \\
\gamma_{x y . \max }
\end{array}\right\}=B_{S}\left(y_{\varepsilon}\right) \cdot e(x) \\
B_{S}\left(y_{\varepsilon}\right)=\left[\begin{array}{ccc}
1 & -y_{\varepsilon} & 0 \\
0 & 0 & 1
\end{array}\right]
\end{gathered}
$$

The internal forces at a section level are given by:

$$
\begin{gathered}
N=\int \sigma_{x} d A=\text { Axial force } \\
V=\int \tau_{x y} d A=\text { Shear force } \\
M=-\int y_{\varepsilon} \sigma_{x} d A=\text { Bending Moment }
\end{gathered}
$$

The section generalized forces can be written in a matrix format as follows:

$$
f_{s}(x)=\int B_{s}{ }^{T}\left(y_{\varepsilon}\right) \cdot \sigma\left(x, y_{\varepsilon}\right) d A
$$

where:

$$
f_{s}(x)=\left\{\begin{array}{l}
N \\
M \\
V
\end{array}\right\}, \quad B_{s}\left(y_{\varepsilon}\right)=\left[\begin{array}{ccc}
1 & -y_{\varepsilon} & 0 \\
0 & 0 & 1
\end{array}\right], \quad \sigma\left(x, y_{\varepsilon}\right)=\left\{\begin{array}{c}
\sigma_{x} \\
\tau_{x y}
\end{array}\right\}
$$

Taking into account the section discretization into fibers/layers, the total forces on the beam section are easily computed through the summation of the contributions of each $i$-th fiber/layer:

$$
N=\sum_{i=1}^{n . l a y e r} \sigma_{x}^{i} A^{i}, \quad V=\sum_{i=1}^{n . l a y e r} \tau_{x y}^{i} A^{i}, \quad M=-\sum_{i=1}^{n . l a y e r} \sigma_{x}^{i} y_{\varepsilon}^{i} A^{i}
$$

where $A^{i}$ is the area of the $\mathrm{i}$-th fiber/layer.

In order to determine the normal and the shear stress for the $i$-th fiber / layer $\left(\sigma_{x}{ }^{i}, \tau_{x y}{ }^{i}\right)$ a bi-axial fiber constitutive model is developed according to the MCFT, as it is stated previously (Figure 3, $\sigma_{x}^{i}=f_{c x}^{i}$ ).

According to the above guidelines the section forces are determined based on known sectional deformations. In case where the section forces are known and the section deformations are the desirable results iterations are necessary (this means that the roots are searched deformations, whereas the deviation from the desired section forces is negligible or zero).

The tangent section stiffness matrix $k_{s}$ is defined as the derivative of the section force vector $f_{s}$ with respect to the section deformation vector $e$, where the explicit reference to $x$ is dropped for brevity of notation: 


$$
\begin{gathered}
k_{S}=\left[\begin{array}{lll}
\frac{\partial f_{s_{1}}}{\partial e_{1}} & \frac{\partial f_{s_{1}}}{\partial e_{2}} & \frac{\partial f_{s_{1}}}{\partial e_{3}} \\
\frac{\partial f_{s_{2}}}{\partial e_{1}} & \frac{\partial f_{s_{2}}}{\partial e_{2}} & \frac{\partial f_{s_{2}}}{\partial e_{3}} \\
\frac{\partial f_{S_{3}}}{\partial e_{1}} & \frac{\partial f_{s_{3}}}{\partial e_{2}} & \frac{\partial f_{s_{3}}}{\partial e_{3}}
\end{array}\right] \\
k_{s}=\frac{\partial f_{s}}{\partial e}=\int B_{s}{ }^{T}\left(y_{\varepsilon}\right) \cdot \frac{d \sigma(x, y)}{\partial \varepsilon(x, y)} \cdot \frac{\partial \varepsilon(x, y)}{\partial e} d A=\int B_{s}{ }^{T}\left(y_{\varepsilon}\right) \cdot \frac{d \sigma(x, y)}{d \varepsilon(x, y)} B_{S}\left(y_{\varepsilon}\right) d A \\
\sigma\left(x, y_{\varepsilon}\right)=\left\{\begin{array}{c}
\sigma_{x} \\
\left.\tau_{x y}\right\}
\end{array} \quad \varepsilon\left(x, y_{\varepsilon}\right)=\left\{\begin{array}{c}
\varepsilon_{x} \\
\gamma_{x y}
\end{array}\right\}\right. \\
\frac{d \sigma(x, y)}{d \varepsilon(x, y)}=\left[\begin{array}{cc}
E_{m} & 0 \\
0 & G_{m}
\end{array}\right]
\end{gathered}
$$

where $E_{m}$ and $G_{m}$ are the tangent moduli of the stress - strain relations at a point $m$ of the section approximated here by $E_{\text {sec }}, G_{\text {sec }}$ (Table 1, Figure 3).

\section{Embedded Algorithms in Phaethon Software}

The most studied and tested structural form for deeper understanding of the structural behaviour in reinforced concrete structures is the simple cantilever column under various types of loading. Although it is a very simple case, its numerical simulation with all interacting deformation mechanisms is still yet a very challenging task to accomplish. Towards this need and for the case of shear-critical cantilever reinforced concrete columns the idea of "Phaethon" (i.e. "the Shining" in ancient Greek) was born. In this section the algorithms embodied in this Windows application are presented.

\subsection{Moment-Curvature Algorithm}

Through the cross sectional analysis are determined the unknown moment $M$ (and the associated axial deformation $\varepsilon_{0}$ ) for given curvature $\varphi$ increments and the unknown shear force $V$ for given shear strain $\gamma$ increments with or without the presence of constant axial load $N$. The system of equations for section equilibrium can be established as follows:

$$
\left\{\begin{array}{c}
\left.N-N_{r}\left(\varepsilon_{0}, \varphi, \gamma\right)=0\right) \\
\left.\mathrm{M}-\mathrm{M}_{r}\left(\varepsilon_{0}, \varphi, \gamma\right)=0\right) \\
\left.V-V_{r}\left(\varepsilon_{0}, \varphi, \gamma\right)=0\right)
\end{array}\right\}
$$

The explicit dependence of the resisting forces is noted. With $N, \varphi$ and $\gamma$ given, the first equation is used to solve for $\varepsilon_{0}$; then this value is substituted along with the given $\varphi$ and $\gamma$ into the second and third equation to determine $M$ and $V$. The resisting axial force in the first Equation 21 is expanded with Taylor series and the higher than linear terms are truncated:

$$
N-\left[N_{r}\left(\varepsilon_{00}, \varphi_{0}\right)+\frac{\partial N}{\partial \varepsilon_{0}} \Delta \varepsilon_{0}+\frac{\partial N}{\partial \varphi} \Delta \varphi+\frac{\partial N}{\partial \gamma} \Delta \gamma\right]=0
$$

where the second subscript 0 denotes the initial guess for the solution. Given the axial force $N$, the curvature increment $\Delta \varphi$ and the shear strain increment $\Delta \gamma$, the above equation can be solved for $\Delta \varepsilon_{0}$ :

$$
\Delta \varepsilon_{0}=\left(\frac{\partial N}{\partial \varepsilon_{0}}\right)^{-1} \cdot\left(N_{u}-\frac{\partial N}{\partial \varphi} \Delta \varphi-\frac{\partial N}{\partial \gamma} \Delta \gamma\right) \text { with } N_{u}=N-N_{r}\left(\varepsilon_{01}, \varphi_{1}\right)
$$

The numerical solution is distinguished by the incrementation phase, which consists of the application of the curvature and shear strain increment, and by the equilibrium iterations under fixed axial force, curvature and shear strain. The axial force is applied in an initial step under zero curvature and zero shear strain. Therefore, the following algorithm is applied in Phaethon for this task: 
Given section geometry and material properties, axial force $N$, curvature increment $\Delta \varphi$ and shear strain increment $\Delta \gamma$ ( $e$ is the section's strain vector and $f_{s}$ is the resisting section forces -see Section 2)

\section{Incrementation for $k=1 . . m$}

1. Initial guess $e_{0}^{(k)}=e^{(k-1)}$ the solution at $k-1$ with $e^{(0)}=0$

2. Determine $f_{s}^{(k)}=f_{s}\left(e_{0}^{(k)}\right)$ and $k_{s}^{(k)}=k_{s}\left(e_{0}^{(k)}\right)$ according to Section 2

3. Determine $N_{u}^{(k)}=N-f_{s 1}^{(k)}$ and $\Delta \varepsilon_{0}^{(k)}=\left(\frac{\partial N}{\partial \varepsilon_{0}}\right)^{-1} \cdot\left(N_{u}^{(k)}-\frac{\partial N}{\partial \varphi} \Delta \varphi-\frac{\partial N}{\partial \gamma} \Delta \gamma\right)$ where

$$
\frac{\partial N}{\partial \varepsilon_{0}}=k_{s 11}^{(k)}, \frac{\partial N}{\partial \phi}=k_{s 12}^{(k)} \text { and } \frac{\partial N}{\partial \gamma}=k_{s 13}^{(k)}
$$

4. Update solution $e_{1}^{(k)}=e_{0}^{(k)}+\left(\begin{array}{c}\Delta \varepsilon_{0}^{(k)} \\ \Delta \varphi \\ \Delta \gamma\end{array}\right)$

\section{Iteration for $\boldsymbol{i}=1 . . n$ and constant $\boldsymbol{k}$ (skip superscript)}

1. Determine $f_{s}=f_{s}\left(e_{i}\right)$ and $k_{s}=k_{s}\left(e_{i}\right)$

2. Determine $N_{u}=N-f_{s 1}$ and $\Delta \varepsilon_{0}=\left(\frac{\partial N}{\partial \varepsilon_{0}}\right)^{-1} \cdot\left(N_{u}\right)$ where $\frac{\partial N}{\partial \varepsilon_{0}}=k_{s 11}$

3. Update solution $e_{i+1}=e_{i}+\left(\begin{array}{c}\Delta \varepsilon_{0} \\ 0 \\ 0\end{array}\right)$

Back to iteration Step 1 until the error norm satisfies specified tolerance. On convergence the final state is updated thus determining the bending moment and shear force and the algorithm returns to Incrementation phase at Step 1.

\subsection{Pushover Algorithm}

For the Pushover analysis of a cantilever shear-critical RC column in Phaethon, the sectional model (either rectangular or circular) established in Section 2 is employed along with the anchorage model in the footing established in Tastani and Pantazopoulou (2013). An increasing lateral point load at the tip of the cantilever is applied (Figure 6) and a unique fiber element is assigned to the entire height of the cantilever column with the number of Gauss-Lobatto integration points selected by the user. The user is selecting also the analysis step of lateral load $V$ to be applied in the Pushover and the total number of steps until the maximum load (Modified Compression Field Theory in the fiber approach as described in Bentz (2000) cannot capture the descending branch of shear-critical columns that is why a load-control procedure was selected to be embedded in Phaethon). The maximum load in Phaethon is the load of last step of convergence of the algorithm in incremental form. It should be underlined that in reality the shear-critical column's ascending response is followed by a descending branch of failure; however the proposed algorithm is limited by strength attainment. After the maximum load the descending branch of the capacity curve is defined as the line connecting the maximum load point with the point at axial failure as defined in terms of drift by Elwood and Moehle (2005) and 20\% of the attained maximum load as residual load at axial failure.

For each point load at the tip of the cantilever (Figure 6) the corresponding shear force at the assigned column's sections (integration points) is equal to that load (constant shear diagram). Then the bending moment for each section is defined based on the moment at the base $M_{0}$ which is the product of the tip lateral load and the given shear span of the cantilever column, as follows:

$$
M(x)=M_{0} \cdot\left(1-x / L_{s}\right)
$$

where $x$ counts from the support $(x=0)$ to the point load at the free edge of the cantilever $\left(x=L_{s}\right)$. The concentric axial load (tensile or compressive) applied at the tip of the cantilever is also constant throughout the pushover analysis and along the length of the cantilever and therefore each column's section has an axial force value equal to the one applied at the tip. Following this procedure the vector $f_{s}$ which is the resisting section forces (see 
Section 2) should converge to the above defined section forces based on the moment, shear and axial load diagram of the cantilever column under constant axial load and gradually increasing lateral tip point loading.

The following algorithm is applied in Phaethon to achieve this convergence:

Given the section forces $s$ i.e. an axial force $N$, a bending moment $M$ and a shear force $V$, the equilibrium equation between applied and resisting section forces is set up:

$$
s_{u}(e)=s-f_{s}(e)=0
$$

The Newton-Raphson algorithm for the solution of the system of three nonlinear equations is:

1. Given the nonlinear equations $s_{u}(e)=0$ and a guess of the solution $\mathrm{e}_{0}$.

2. For $i=0 \ldots n$ determine function value $s_{u}\left(e_{i}\right)$ and derivatives $k_{s}\left(e_{i}\right)$ (Section 2)

3. Determine correction to previous solution estimate $\Delta e_{i}=s_{u}\left(e_{i}\right) / k_{s}$

4. Update solution estimate $e_{i+1}=e_{i}+\Delta e_{i}$

Return to step 2 until the error norm is smaller than specified tolerance. On convergence determine the resisting forces for the final deformations.

It should be underlined that for the cases of "pure compression" or "pure tension" with the angle of inclination of principal stresses / strains (angle of principal axis 2 with respect to $x$-axis) being zero or $\pi / 2$ respectively than no iteration is applied but the fiber state determination is defined by entering directly on the constitutive law of concrete (Section 2, Table 1) without defining the rotation of principal axes.

After convergence of the section forces along the length of the cantilever column to the correct values, the axial deformation, curvature and shear strain is determined for each section. Integrating the curvatures (Figure 6) along the shear span of the cantilever column leads to the rotation of the cantilever column due to flexure and can be easily transformed to lateral displacement due to flexure $\Delta_{o}{ }^{f}$ by multiplying with the shear span. Then, integration of the shear strains (Figure 6) of the sections along the length of the cantilever column (integration points) leads to the lateral displacement $\Delta_{o}^{s h}$ due to shear mechanism of the cantilever column. Finally, the rotation and the displacement $\Delta_{o}{ }^{s l}$ due to pull-out of the tensile reinforcement (Figure 6) is determined based on the theory established in Tastani and Pantazopoulou (2013). All the above contributions (flexure, shear and anchorage) are added together to define the total lateral displacement (i.e., $\Delta_{o}=\Delta_{o}^{f}+\Delta_{o}^{s h}+\Delta_{o}^{s l}$ ) of the cantilever column at each lateral load step and to obtain the capacity curve of the column until maximum lateral load (Figure 6).

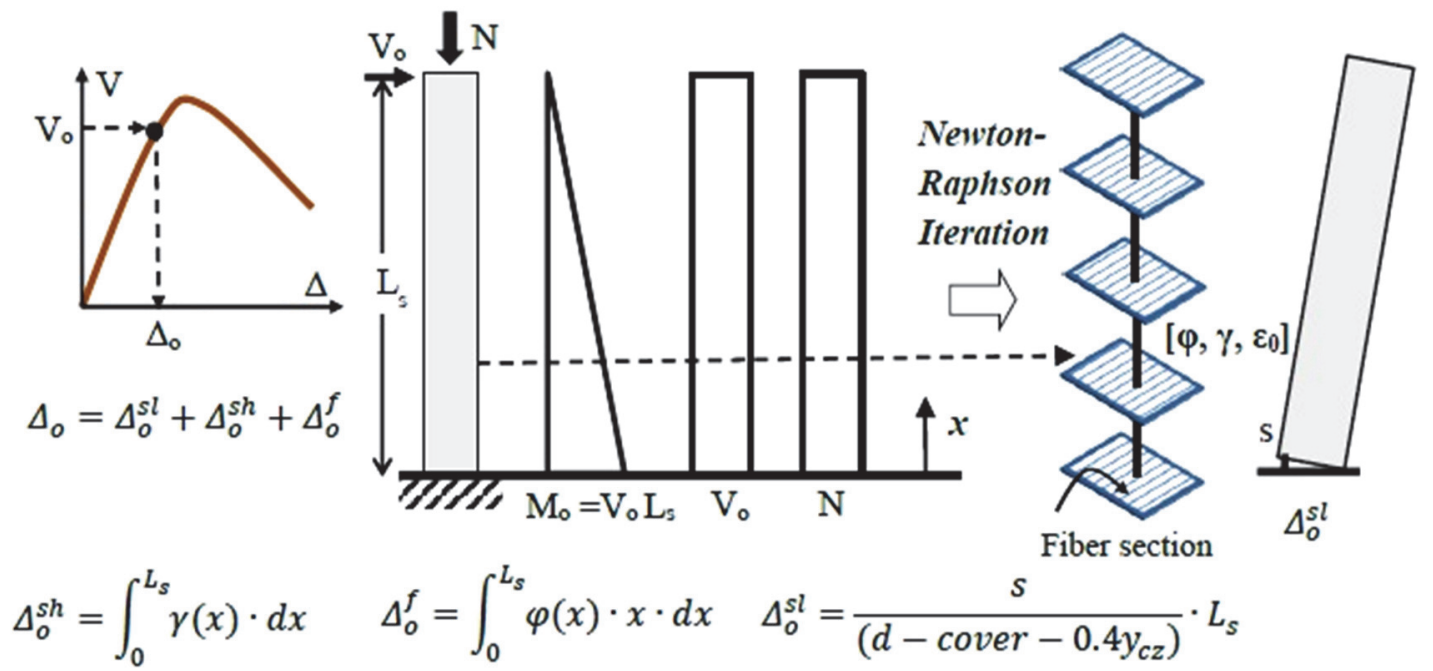

Figure 6. Pushover Analysis in Phaethon

\section{Correlation with Experimental Results}

This section presents the correlation of the shear-flexure capacity curves obtained with pushover analysis by Phaethon with the experimental responses of shear-critical RC columns selected from literature. In the correlation are also included for comparison capacity curves obtained from flexural fiber beam/column based toolbox FEDEAS Lab (Filippou, 2004) and from MCFT-based software and dual-section analysis Response 
2000 (Bentz, 2000)

The shear capacity degradation curve of RC columns as a function of displacement ductility is approached by EN 1998-3 (2005) and ASCE-SEI 41 (2007) and can be used as the basic criterion in order to detect shear failure before or after flexural yielding depending on the point of intersection with flexural capacity curve (Figure 7). To this end, it is necessary to define the flexural capacity curve based on classic flexural analysis and combine it with shear capacity curve in order to define the strength and deformation of the RC column at shear failure. This procedure is adopted in this section in order to initially detect whether the columns under study will fail in shear before or after flexural yielding and therefore to judge whether "Phaethon" tool is applicable.

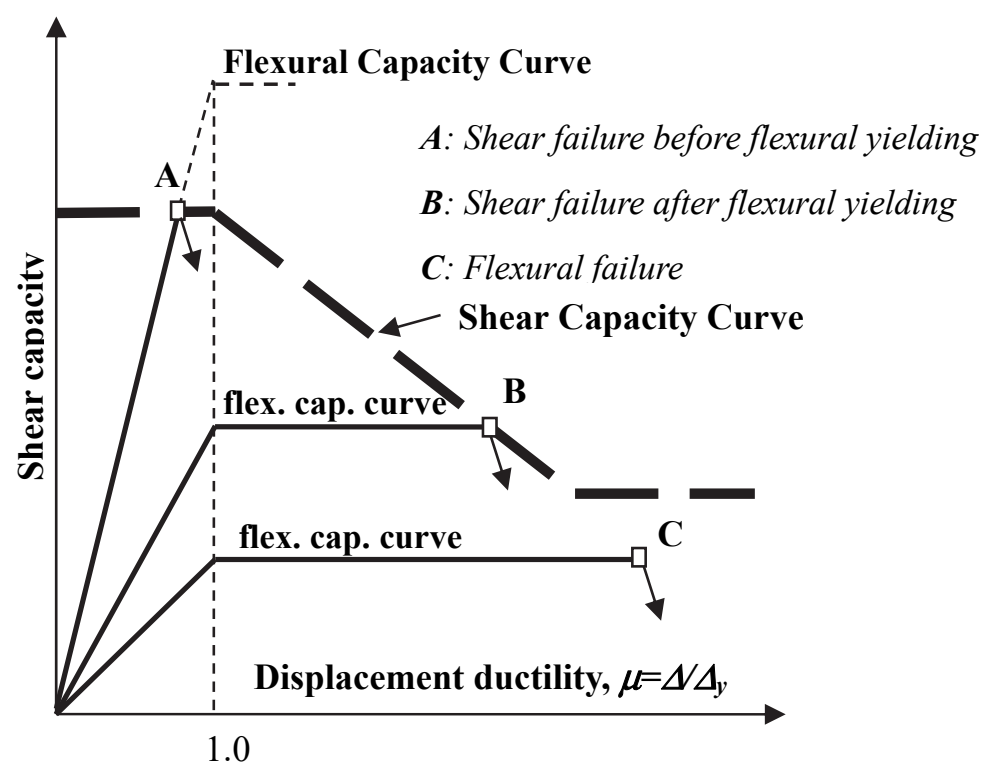

Figure 7. Shear-strength degradation model

The following Equation (26) for estimation of the shear strength degradation with ductility of RC columns is proposed by the code for seismic rehabilitation of existing buildings of the American Society of Civil Engineers ASCE/SEI 41:

$$
\begin{gathered}
V_{R}=V_{c}+V_{w}= \\
=k\left(\mu_{\Delta}\right)\left[\left(0.5 \sqrt{f_{c}} /\left(L_{s} / d\right)\right) \sqrt{1+N /\left(0.5 A_{g} \sqrt{f_{c}}\right)}\right] 0.8 A_{g}+k\left(\mu_{\Delta}\right)\left[A_{s w} f_{y w} d_{e} / S\right]
\end{gathered}
$$

where:

$\boldsymbol{V}_{\boldsymbol{c}}$ : concrete contribution in shear resistance; $\boldsymbol{V}_{\boldsymbol{w}}$ : shear reinforcement contribution is shear resistance; $\boldsymbol{d}_{\boldsymbol{e}}$ : is the effective depth; $\boldsymbol{L}_{\boldsymbol{s}}$ : is shear span of the column; $\boldsymbol{N}$ : is the compressive axial force (positive, taken as being zero for tension); $\boldsymbol{A}_{\boldsymbol{g}}$ : is the gross cross-sectional area of the column; $\boldsymbol{A}_{\boldsymbol{s} \boldsymbol{w}}$ : is the cross-sectional area of the stirrup; $\boldsymbol{S}: \quad$ is the centerline spacing of stirrups. If the spacing is equal or greater than $d / 2$ of the column then the contribution of steel reinforcement $V_{w}$ in shear strength should be taken as half of its estimated value from the above equation. In addition if the spacing is equal or greater than $d$ then zero shear strength contribution from steel reinforcement $V_{w}$ should be considered; $\boldsymbol{f}_{c}$ : is the concrete compressive strength; $\boldsymbol{k}\left(\boldsymbol{\mu}_{\Delta}\right)$ : is the shear strength reduction factor that depends on displacement ductility $m_{D}$. (If $\mu_{\Delta} \leq 2$ then $\mathrm{k}\left(\mu_{\Delta}\right)=1$, if $\mu_{\Delta}>6$ then $\mathrm{k}\left(\mu_{\Delta}\right)$ $=0.6$, and if $2<\mu_{\Delta}<6$ then the $\mathrm{k}\left(\mu_{\Delta}\right)$ varies linearly between the proposed values. $)$. 
EN 1998-3 (2005) proposes the following expression for the shear strength degradation with ductility:

$$
\begin{aligned}
V_{R}= & {\left[\left(d-y_{c z}\right) / 2 L_{s}\right] \min \left(N ; 0.55 A_{c} f_{c}\right)+\left[1-0.05 \min \left(5 ; \mu_{\Delta}{ }^{p l}\right)\right] . } \\
& \left\{0.16 \max \left(0.5 ; 100 \rho_{t o t}\right)\left[1-0.16 \min \left(5 ; L_{s} / h\right)\right] \sqrt{f_{c}} A_{c}+V_{w}\right\}
\end{aligned}
$$

where $\boldsymbol{d}: \quad$ is the depth of cross-section (equal to the diameter $D$ for circular sections); $\boldsymbol{y}_{\boldsymbol{c} z}$ : is the compressive zone depth; $\boldsymbol{N}$ : is the compressive axial force (positive, taken as being zero for tension); $\boldsymbol{L}_{\boldsymbol{s}}: M / V$ ratio moment/shear at the end section; $\boldsymbol{A}_{\boldsymbol{c}}$ : is the cross-section area, taken as being equal to $b_{w} d_{e}$ for a cross-section with a rectangular web of width (thickness) $b_{w}$ and effective depth $d_{e}$ or to $\pi D_{c}{ }^{2} / 4$ (where $D_{c}$ is the diameter of the concrete core to the inside of the hoops) for circular sections; $\boldsymbol{f}_{\boldsymbol{c}}$ : is the concrete compressive strength; $\boldsymbol{\rho}_{\text {tot }}:$ is the total longitudinal reinforcement ratio; $\mu_{\Delta}^{p l}=\mu_{\Delta}-1$.

$\boldsymbol{V}_{\boldsymbol{w}}$ : is the contribution of transverse reinforcement to shear resistance, taken as being equal to:

a) for cross-sections with rectangular web of width (thickness) $b_{w}$ :

$$
V_{w}=\rho_{w} b_{w} z f_{y w}
$$

where $\boldsymbol{\rho}_{\boldsymbol{w}}$ : is the transverse reinforcement ratio; $\boldsymbol{z}$ : is the length of the internal lever arm (taken as being equal to $d_{e^{-}} d^{\prime}$ in beams, columns (where $d^{\prime}$ is the distance of the extreme compression fiber to the level of the compression reinforcement); and $\boldsymbol{f}_{y w}$ : is the yield stress of the transverse reinforcement;

b) for circular cross-sections:

$$
V_{w}=\frac{\pi}{2} \frac{A_{s w}}{S} f_{y w}(D-2 c)
$$

where $\boldsymbol{D}: \quad$ is the diameter of the section; $\boldsymbol{A}_{\boldsymbol{s} \boldsymbol{w}}$ : is the cross-sectional area of a circular stirrup; $\boldsymbol{S}:$ is the centerline spacing of stirrups; $\boldsymbol{f}_{\boldsymbol{y} \boldsymbol{w}}$ : is the yield stress of the transverse reinforcement; $\boldsymbol{c}$ : is the concrete cover.

\subsection{Rectangular Shear-Critical Columns}

This first selected rectangular column for comparison is Specimen 1 by the experimental campaign of Sezen and Moehle (2006) that failed in shear after flexural yiedling. Its properties are reported in Table 2. Figure 8 compares the experimental response (by red) with the analytical flexural capacity curve (by blue) and the shear capacity obtained by EN 1998-3 (by green) and by ASCE-SEI 41 (by black) (here the yielding displacement in both shear-strength degradation models is defined by the flexural analysis based on the applied fiber element included in FEDEAS Lab; It can be read from the end of the initial plateau of EN 1998-3 model). The ASCE-SEI 41 estimates a very conservative shear strength as compared to the yielding strength of specimen which would be interpreted as premature brittle failure; EN 1998-3 detects the column's shear failure after yielding in terms of strength but at lower displacement compared to the experimental result.

As it can be seen in Figure 9 the comparison of the capacity curve defined by Phaethon for Specimen 1 (that failed in shear after flexural yielding) until the maximum load is close to the experimental response but also close to the capacity curves by the other already mentioned softwares. The deviation of stiffness close to peak load from Phaethon can be improved if slip from shear span $L_{s}$ is added (Megalooikonomou et al., 2018). Since the latter established methodology refers only to extended flexural yielding it was not incorporated to "Phaethon" software as it would not have been general in simulating shear failures which could occur also before flexural yielding.

Response 2000 doesn't provide the descending branch of the capacity curve due to shear failure after flexural yielding while FEDEAS Lab overestimates the response after maximum load is attained since it doesn't consider any shear-flexure interaction mechanism. Phaethon postdicts both the maximum load but also the descending branch of the response in this case.

Figures 10 and 11 depict the displacement contributions in each pushover analysis step from the various interacting mechanisms as they are defined by Phaethon and they are compared also to the ones measured during the experiment. It can be seen that at yielding (10 $\mathrm{mm}$ total lateral displacement reported by Phaethon) Phaethon 
gives correctly $62 \%$ contribution from flexure, $35 \%$ from Pull-Out and almost 3\% from shear mechanism (which in this case is a bit underestimated).

In Figure 8, the shear capacity curve of Eurocode 8 part 3 (EN 1998-3) for the second selected specimen by Lynn et. al. 1996 doesn't intersect with the flexural capacity curve. This takes place only with the model of ASCE-SEI 41 almost at yielding at a lower strength and displacement compared to the experimental response.

The second selected rectangular column for comparison is by the experimental campaign of Lynn et al. (1996) that failed in shear before flexural yielding. Its properties are presented in the Table 2. As it can be seen in Figure 9 the comparison until the maximum load is close to the experimental response but also close to the capacity curves by the other already mentioned software. Here, Response 2000 underestimates the specimen's strength and doesn't provide the descending branch of the capacity curve due to shear failure before flexural yielding while FEDEAS Lab overestimates the response after maximum load is attained since it doesn't consider any shear-flexure interaction mechanism. Phaethon postdicts correctly both the maximum load but also the descending branch of the response in this case too. However, in all analytical capacity curves the experimental initial stiffness is overestimated. The axial failure (i.e. collapse as defined by Phaethon) is also reached at a lower displacement compared to the experiment. Finally, Figure 10 depicts the displacement contributions in each pushover analysis step from the various interacting mechanisms as they are defined by Phaethon. As it can be seen they are correctly increasing with the applied lateral load.

\subsection{Circular Shear-Critical Columns}

The third selected column for comparison is the circular Specimen 19 by the experimental campaign of Ang et al. 1989 that failed in shear before flexural yielding. Its properties are presented in Table 2. In Figure 12, it can be observed that it is a shear-critical column since both the shear strength degradation models detect shear failure (although wrongly after flexural yielding) at a displacement lower than the corresponding experimental one. The strength at shear failure is better predicted by the model of Eurocode 8 part 3 (EN 1998-3) compared to the alternative of ASCE-SEI 41.

As it can be seen in Figure 9 the comparison of Phaethon response until the maximum load is close to the capacity curves by the other already mentioned software. However, the initial stiffness predicted by Phaethon is higher compared to the experiment although identical to what the other software tools define. Phaethon captures well also the maximum load but not the corresponding displacement. The descending branch as defined by Phaethon follows the experimental strength degradation. The shear strength is better postdicted by Phaethon compared to Response 2000. Finally, Figure 11 depicts the displacement contributions in each pushover analysis step from the various interacting mechanisms as they are defined by Phaethon. As it can be observed they are correctly increasing with the applied lateral load and here due to the aspect ratio of the circular column (short column) the shear mechanism displacement contribution is significant. It should be stated that an incremental filtering (that is omitting some steps from the capacity curve) of the pushover results was applied in this specimen since in some steps the converged displacements given by the program were higher than the previous or the next load steps compared to the current one. This filtering was applied only to the given capacity curve in Figure 9 but the displacement contributions in Figure 10 are given as obtained by the program.

The fourth selected column for comparison is the circular Specimen 20 by the experimental campaign of Ang et al. 1989 that failed in shear after flexural yielding. Its properties are presented in Table 2. In Figure 12, it can be observed that it is a shear-critical column since both the shear strength degradation models detect shear failure after yielding at a displacement lower than the corresponding experimental one. The strength at shear failure is better predicted by the model of Eurocode 8 part 3 compared to the alternative of ASCE-SEI 41. 
Table 2. Details of RC columns failed in shear (units: mm, MPa, kN)

\begin{tabular}{|c|c|c|c|c|c|c|c|c|}
\hline ש & 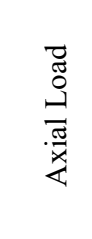 & 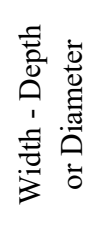 & 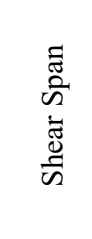 & $\begin{array}{l}\dot{0} \\
0 \\
0 \\
\dot{0} \\
\dot{0}\end{array}$ & 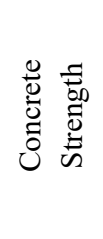 & 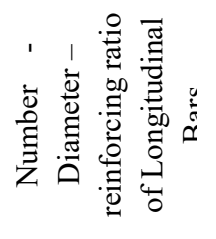 & 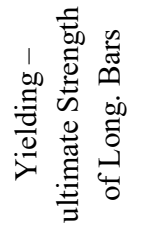 & 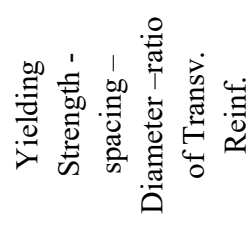 \\
\hline 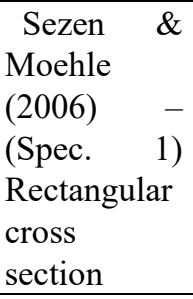 & 667 & $\begin{array}{l}457 \\
457\end{array}$ & 1473 & 65.13 & 21.1 & $\begin{array}{c}8 \\
28.65 \\
0.025\end{array}$ & $\begin{array}{l}434 \\
645\end{array}$ & $\begin{array}{c}476 \\
304.8 \\
9.5 \\
0.0025\end{array}$ \\
\hline $\begin{array}{l}\text { Lynn et. al. } \\
(1996) \\
\text { (Spec. } \\
\text { 3CMH18) } \\
\text { Rectangular } \\
\text { cross } \\
\text { section }\end{array}$ & 1512 & $\begin{array}{l}457 \\
457\end{array}$ & 1473 & 38.1 & 27.6 & $\begin{array}{c}8 \\
31.75 \\
0.03\end{array}$ & $\begin{array}{l}331 \\
496\end{array}$ & $\begin{array}{c}400 \\
457 \\
9.5 \\
0.00082\end{array}$ \\
\hline $\begin{array}{l}\text { Ang et. al. } \\
(1989) \quad- \\
\text { (Spec.19) } \\
\text { Circular } \\
\text { cross } \\
\text { section } \\
\end{array}$ & 432 & 400 & 600 & $18^{*}$ & 34.4 & $\begin{array}{c}20 \\
16 \\
0.032\end{array}$ & $\begin{array}{l}436 \\
679\end{array}$ & $\begin{array}{c}326 \\
80 \\
6 \\
0.0038\end{array}$ \\
\hline $\begin{array}{l}\text { Ang et. al. } \\
(1989) \\
(\text { Spec.20) } \\
\text { Circular } \\
\text { cross } \\
\text { section }\end{array}$ & 807 & 400 & 700 & $18^{*}$ & 36.7 & $\begin{array}{c}20 \\
16 \\
0.032\end{array}$ & $\begin{array}{l}482 \\
758\end{array}$ & $\begin{array}{c}326 \\
80 \\
6 \\
0.0038\end{array}$ \\
\hline
\end{tabular}

*: Cover to Ctr. of Hoop Bars

As it can be seen in Figure 9 the comparison of Phaethon response until the maximum load is close to the capacity curves by the other already mentioned software. However, the initial stiffness predicted by Phaethon is higher compared to the experiment although identical to what the other software tools define. Phaethon, captures well also the maximum load but not the corresponding displacement. The descending branch as defined by Phaethon follows the experimental strength degradation. The axial failure (i.e. collapse as defined by Phaethon) is reached at a lower displacement compared to the experiment. The shear strength is better postdicted by Phaethon compared to Response 2000. Finally, Figure 10 depicts the displacement contributions in each pushover analysis step from the various interacting mechanisms as they are defined by Phaethon. The same idea of filtering as described in the previous circular specimen was applied here too. 
Specimen 1 by Sezen and Moehle 2006
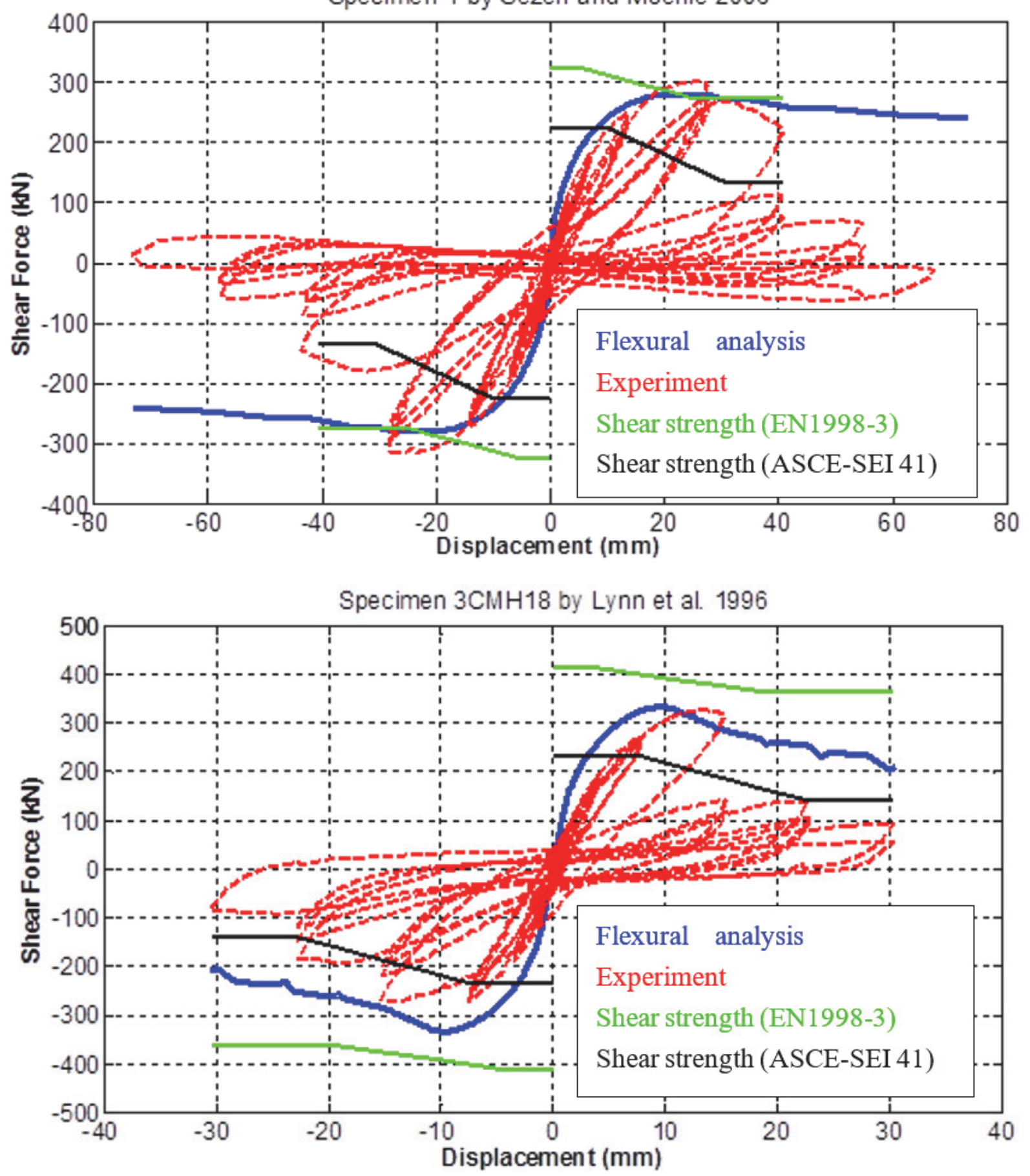

Figure 8. Detection of shear-critical rectangular reinforced concrete columns 

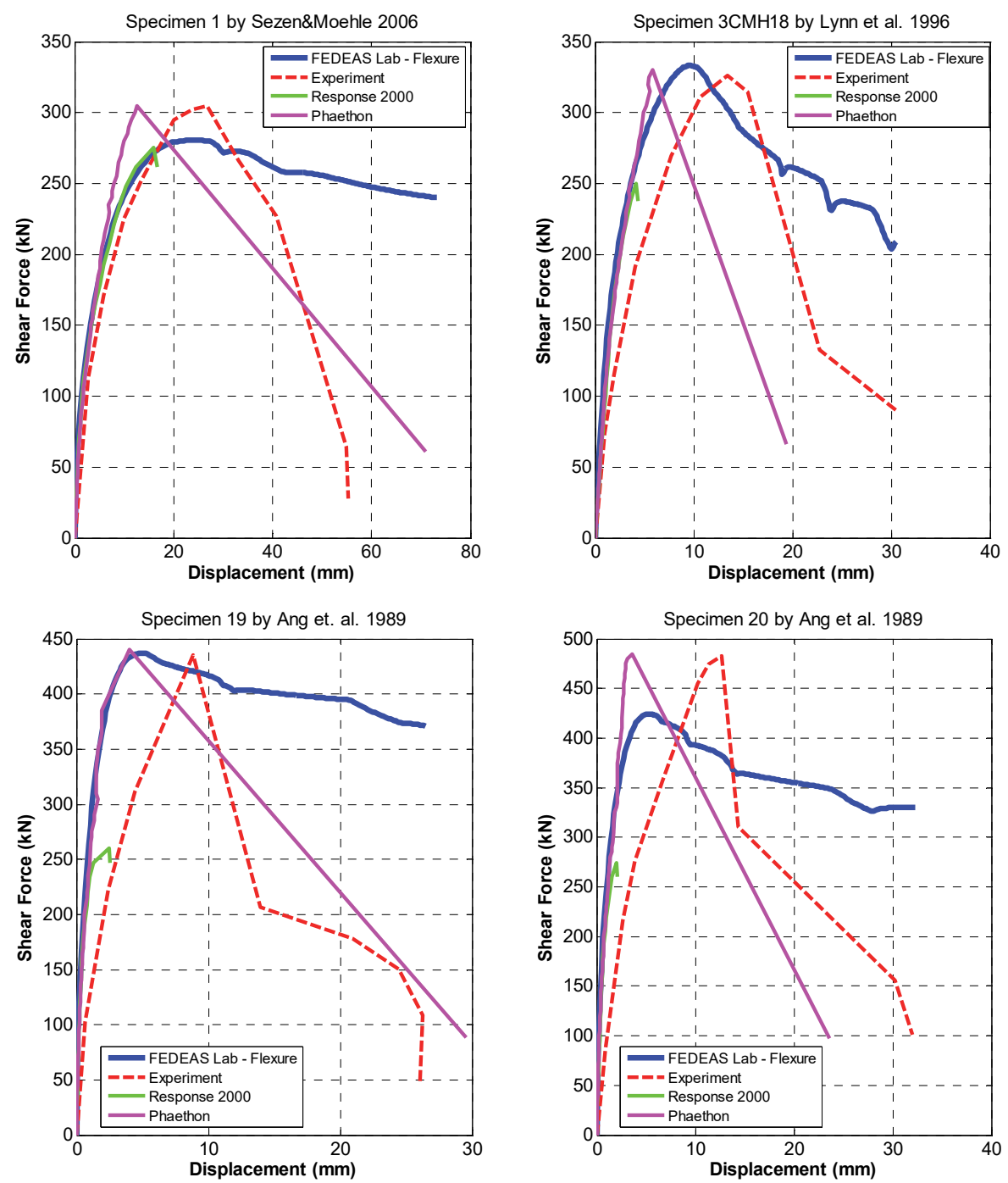

Figure 9. Comparison of the capacity curves provided by Phaethon and other softwares with the experimental responses 

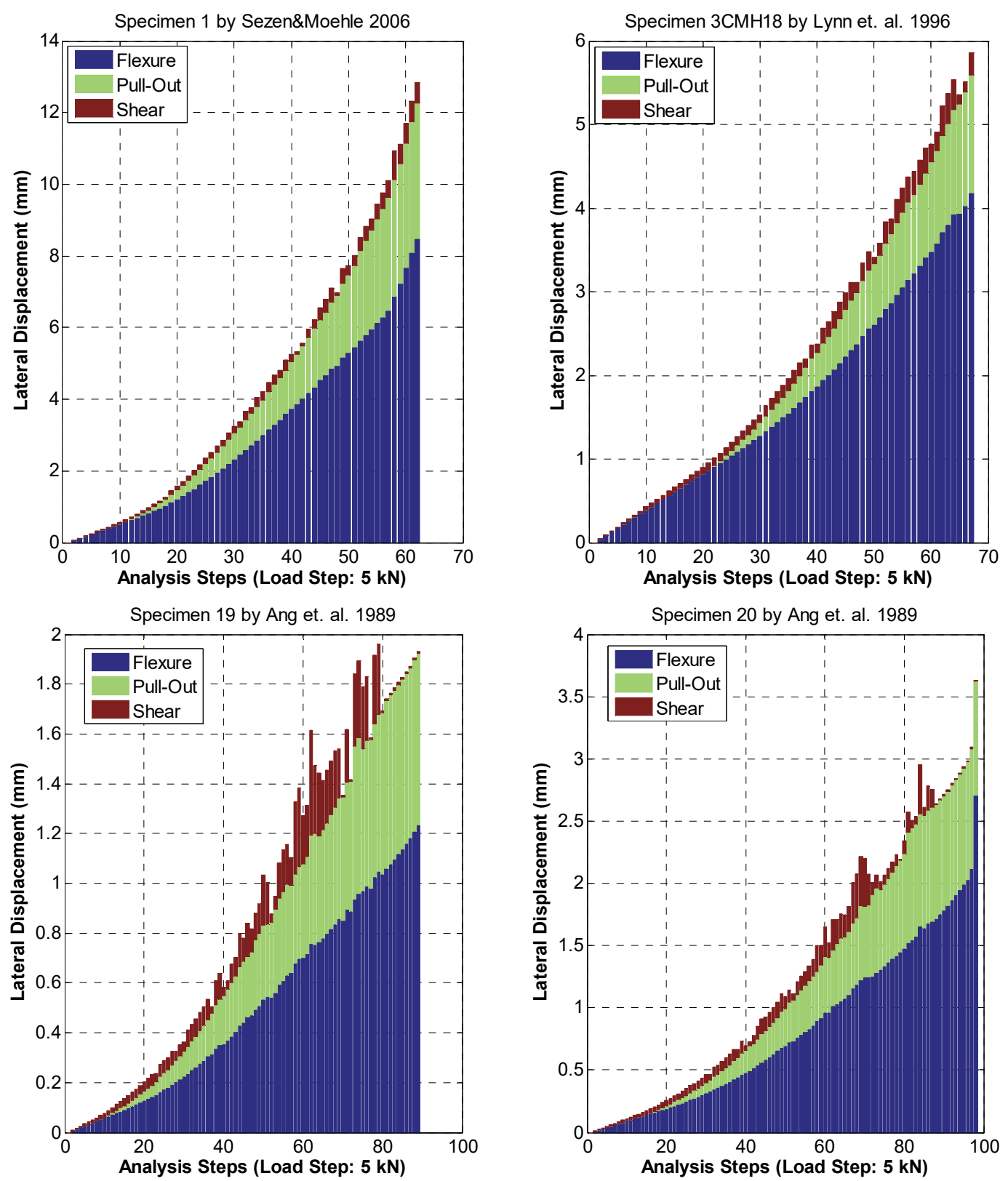

Figure 10. Displacement Contributions from various deformation menchansims included in Phaethon for cantilever columns 

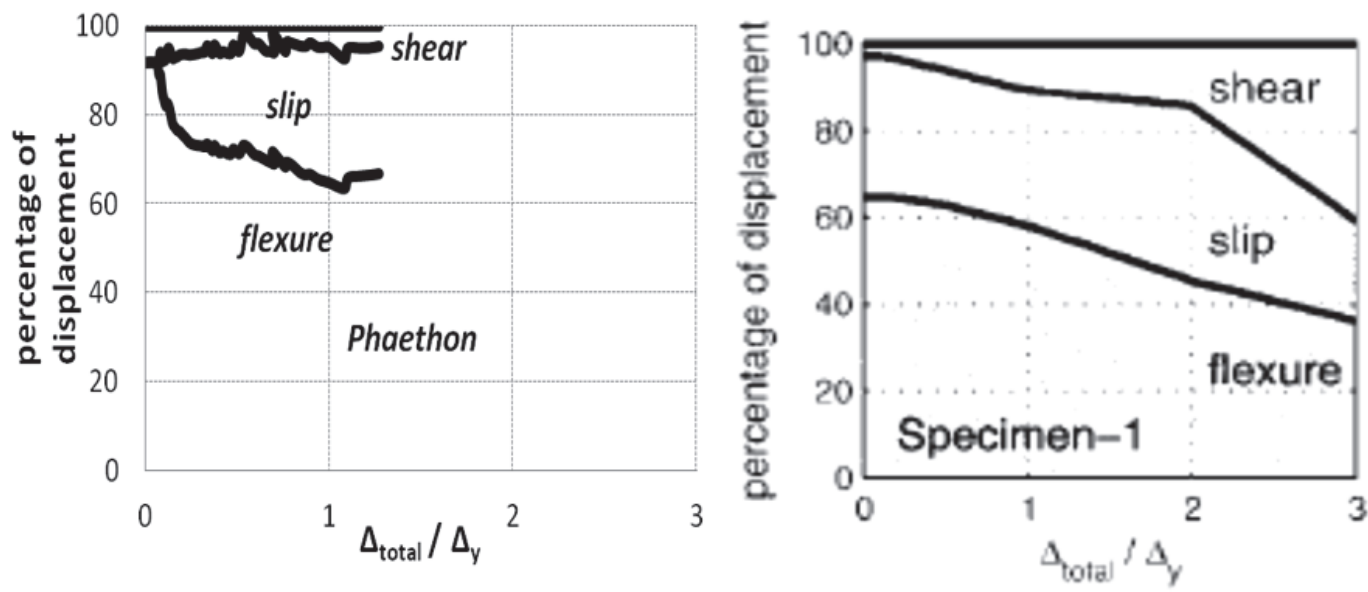

Figure 11. Displacement Contributions from various deformation menchansims included in Phaethon (left) for rectangular column compared to the experiment (right) (Sezen and Moehle (2006))

\section{Parametric Investigation}

The parametric sensitivity of the developed software on the produced capacity curve is investigated in this section considering as a point of reference Specimen 1 by Sezen and Moehle (2006) examined in the preceding section. Parameters considered are the discretization sensitivity of the force-based fiber element of the cantilever column and the effect of axial load, stirrups spacing and shear span length on the produced pushover curve; in each case one parameter is varied at a time keeping the reference values for all other variables (so the possible interaction effects between variables have not been considered in conducting the sensitivity analysis).

In Figure 13 it can be observed the effect on the pushover curve of different amount of Gauss-Lobatto integration points [Ele(Number)IP] along the element as well as the amount of integration points/layers of the Midpoint integration rule along the section $[\operatorname{Sec}($ Number $) \mathrm{L}]$. As expected by increasing the amount of Midpoint layers and Gauss-Lobatto integration points the capacity curve stabilizes to the final result. The deviation from the final result is evident only at the lower amount of integration points both at the section and along the element.

As it can be observed in Figure 14 by increasing the compressive axial load (here is given in normalized form) the shear strength of the column under study is correctly increasing and the deformability of the column is decreasing with lower displacements at maximum load (shear failure) and at point of axial failure (collapse). The effect of stirrups spacing (Figure 15) for a given shear-critical column on the capacity curve produced by Phaethon is negligible until the maximum load (shear strength) but the displacement at axial failure (collapse) is decreasing correctly by increasing the spacing of stirrups. The insensitivity of Phaethon in defining shear strength as a function of stirrups spacing in lightly reinforced columns where shear failure is driven by sparsely spaced stirrups, is justified by the assumptions of the MCFT theory - as described initially in this paper - about smearing of reinforcement. Finally the decrease of the shear span of the cantilever column (Figure 16) correctly produces a more shear-dominant and less deformable reinforced concrete column both at maximum load (shear failure) but also at the point of axial failure (collapse). 

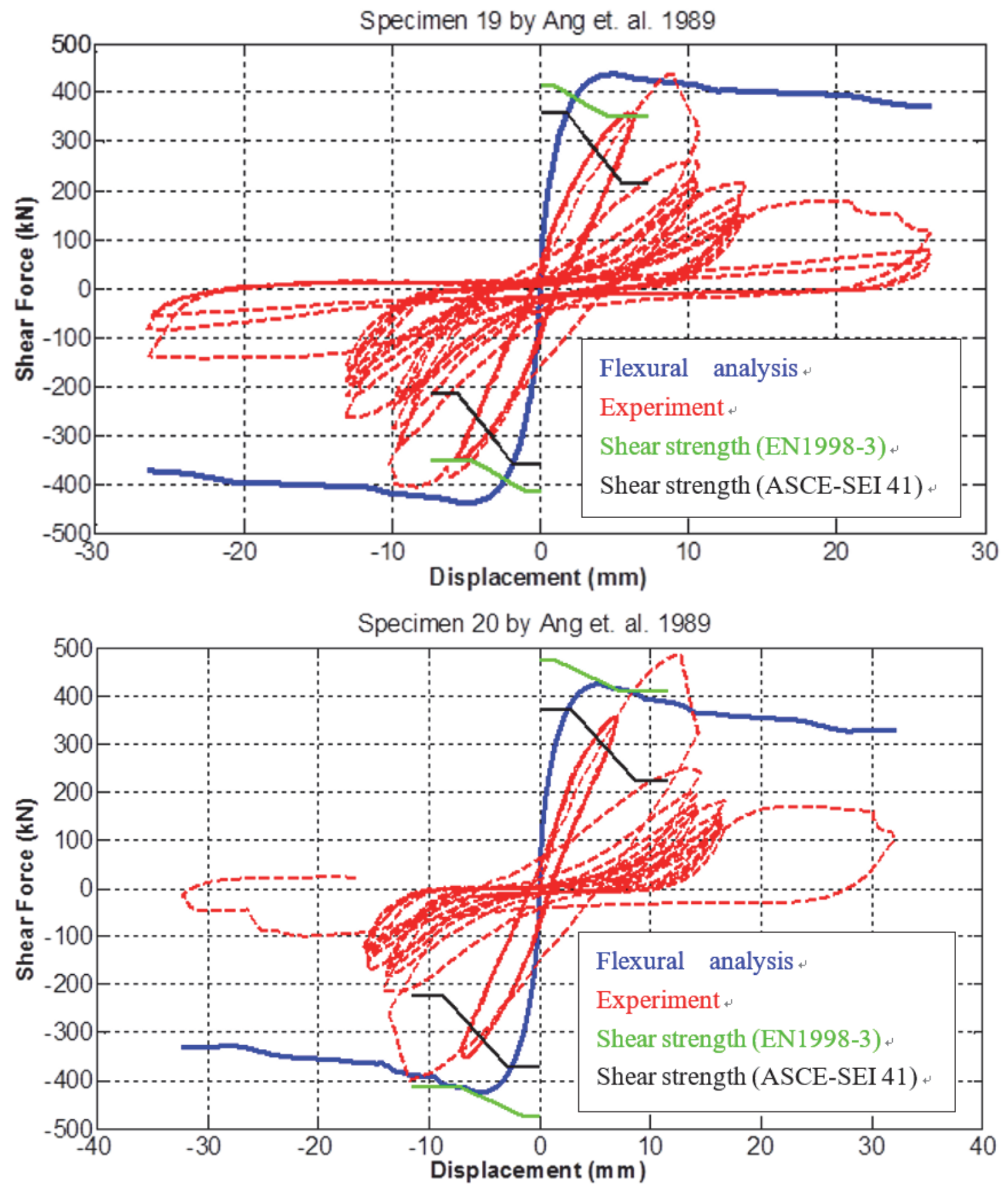

Figure 12. Detection of shear-critical circular reinforced concrete columns 

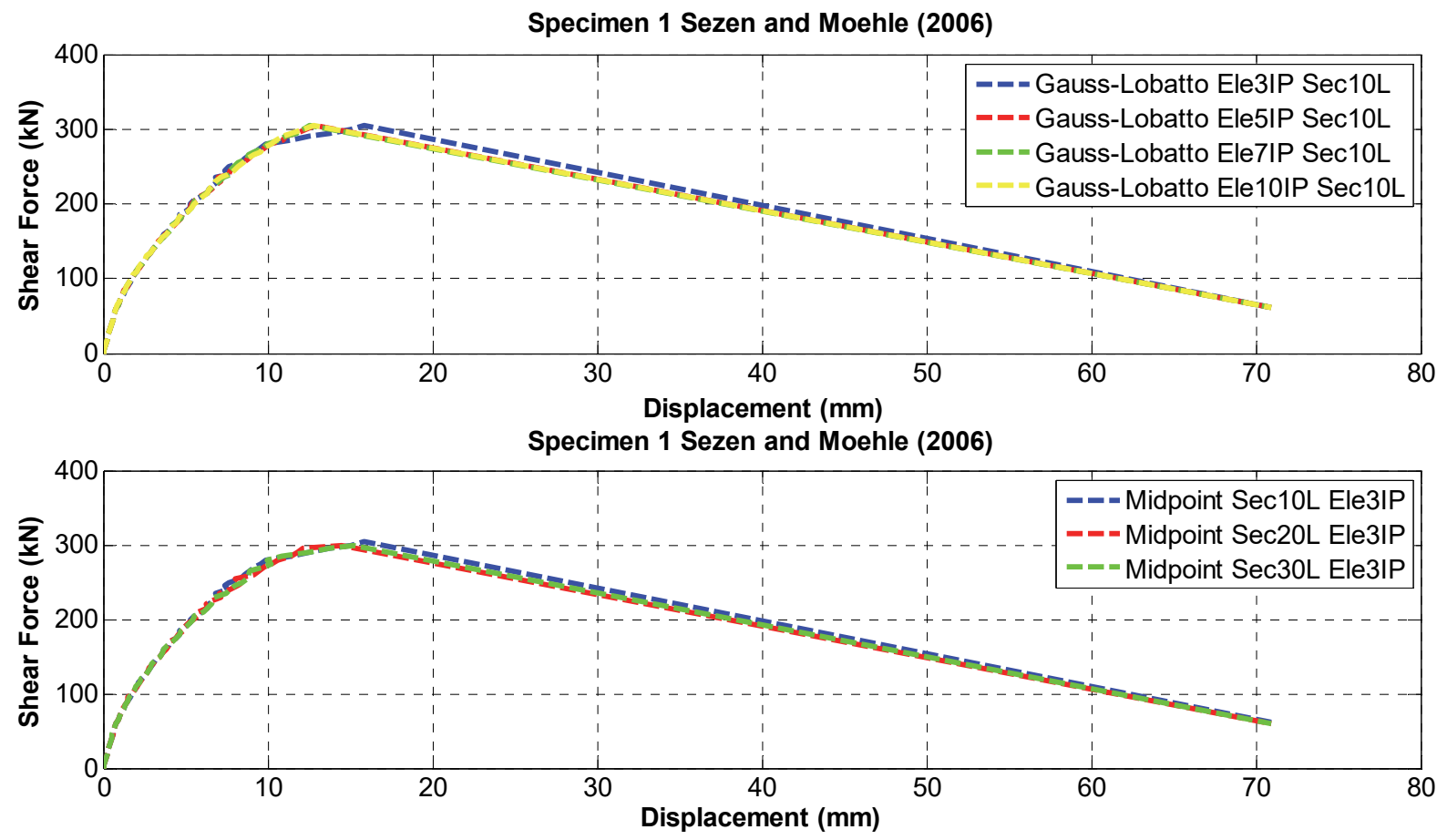

Figure 13. Discretization sensitivity along fiber section and element of the capacity curve provided by Phaethon

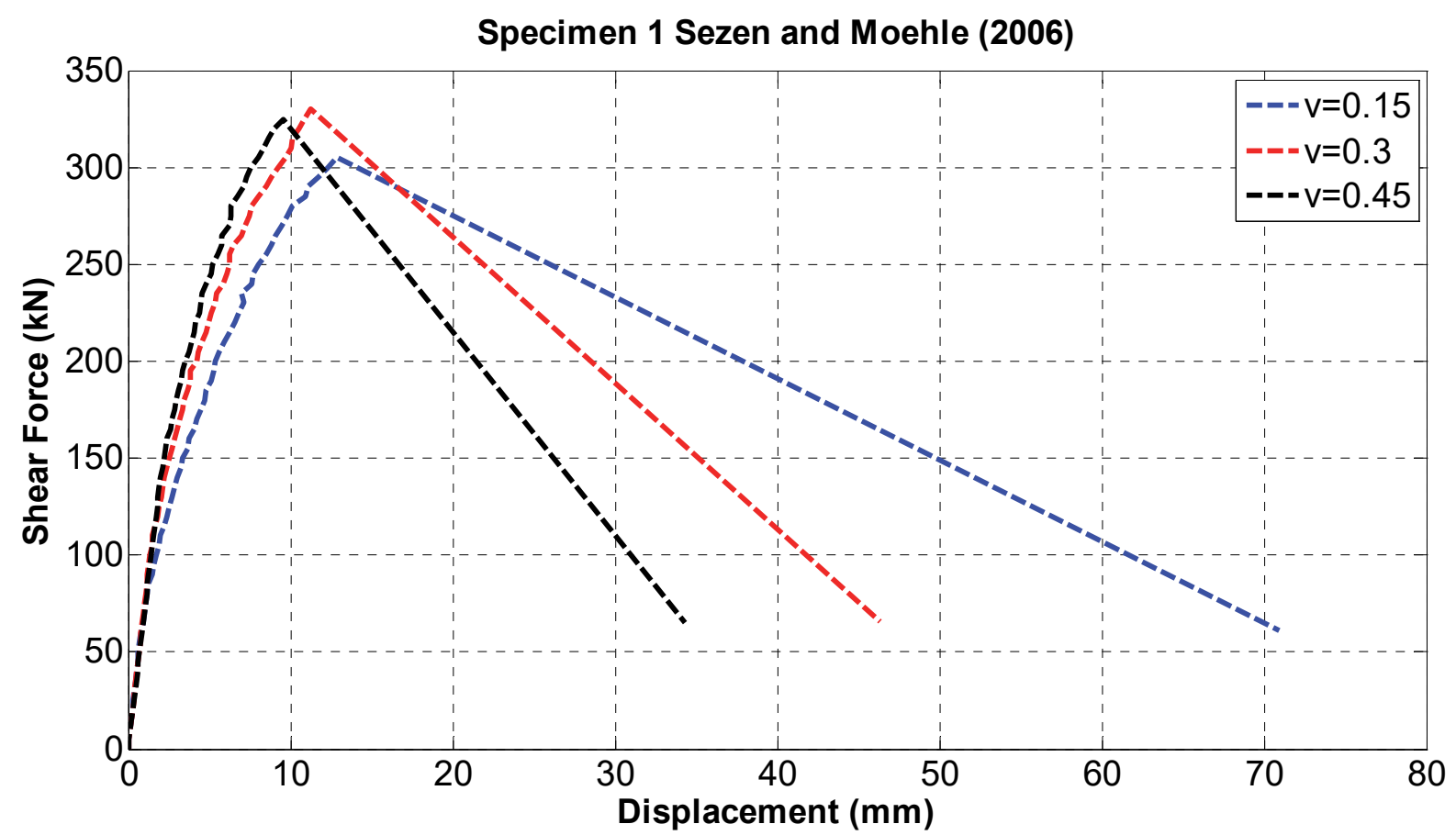

Figure 14. Effect of axial load on capacity curve provided by Phaethon 


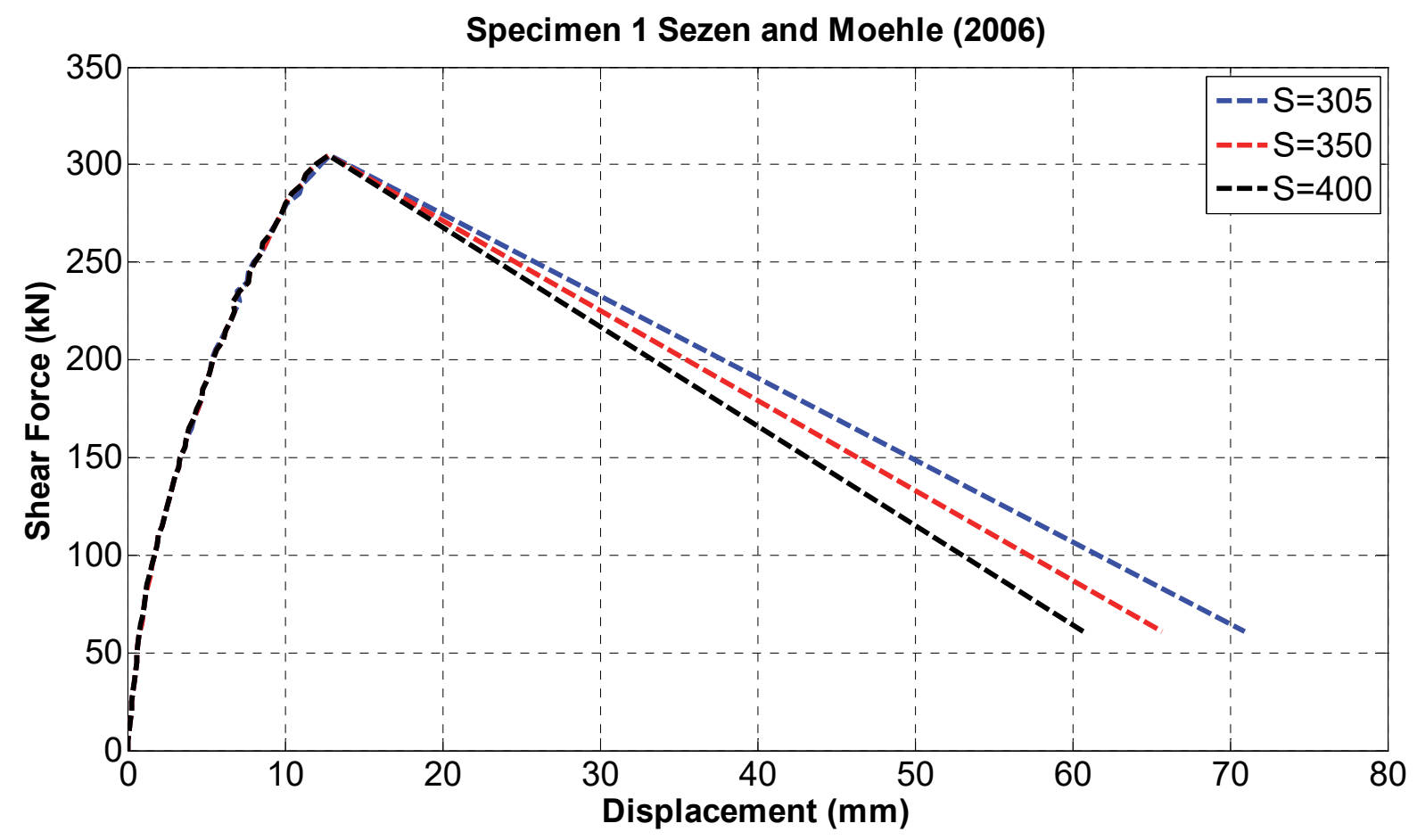

Figure 15. Effect of stirrups spacing on capacity curve provided by Phaethon.

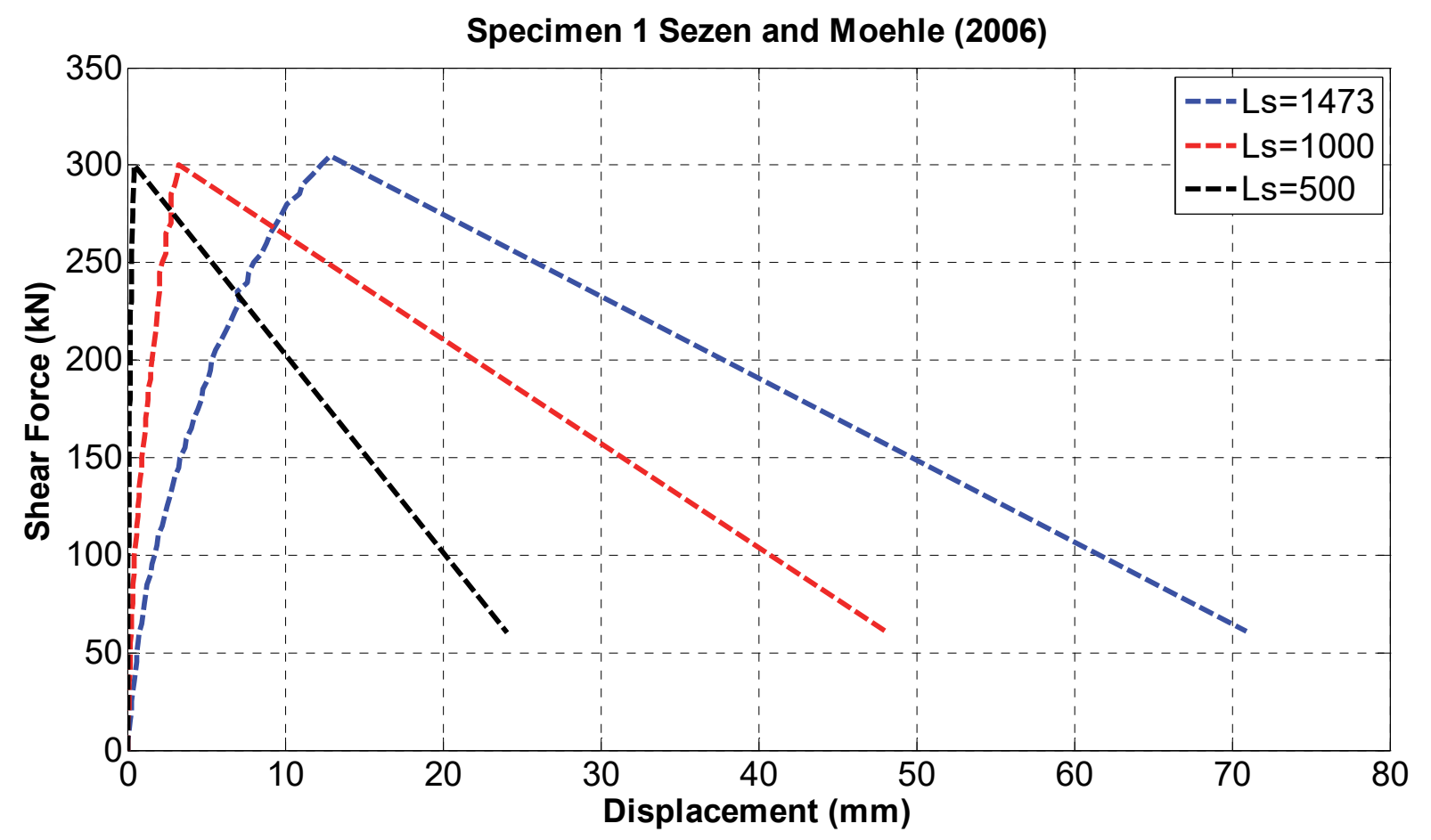

Figure 16. Effect of shear span on capacity curve provided by Phaethon

\section{Conclusions}

In the present paper a force-based fiber beam-column element accounting for shear effects and the effect of tension stiffening was developed, in order to provide an analytical test-bed for simulation and improved understanding of experimental cases where testing of reinforced concrete columns actually led to collapse. The developed fiber-element is incorporated in the stand-alone Windows program Phaethon with user's interface 
written in $\mathrm{C}++$ programming language code that offers the possibility to its user to obtain the capacity curve for shear-critical reinforced concrete cantilever columns taking into account shear - flexure interaction mechanism but also of the important contribution in the final column's lateral displacement, of the pull-out of the inadequate anchorage of the tensile longitudinal reinforcing bars of the column. This is available for both rectangular but also circular reinforced concrete columns. In addition, the software resolves strain, slip and bond distributions along anchorage length. Comparison with experimental results from the literature verifies the capability of this Windows software tool to assess strength and deformation indices of shear-critical reinforced concrete columns. Finally, the moment curvature but also the shear force - shear strain analysis of the sections of these columns is also possible, all based on the Modified Compression Field Theory.

\section{Acknowledgments}

The author would like to thank the Alexander S. Onassis Public Benefit Foundation whose financial support is greatly appreciated. The Phaethon software installation file can be downloaded for free from the following web address: http://bigeconomy.gr/en/phaethon-en/ and it is also available on Researchgate DOI: https://doi.org/10.13140/RG.2.2.31114.57284.

\section{References}

Ang, B. G., Priestley, M. J. N., \& Paulay, T. (1989). Seismic Shear Strength of Circular Reinforced Concrete Columns. ACI Structural Journal, 86(1), 45-59. https://doi.org/10.14359/2634

ASCE/SEI 41 (2007). Seismic Rehabilitation of Existing Buildings. American Society of Civil Engineers, Reston, VA.

Bentz, E. C. (2000). Sectional Analysis of Reinforced Concrete Members. PhD Thesis, Department of Civil Engineering, University of Toronto, Toronto, Canada. Retrieved from http://www.ecf.utoronto.ca/ bentz/r2k.htm

Ceresa, P., Petrini, L., \& Pinho, R. (2007). Flexure-shear fiber beam-column elements for modeling frame structures under seismic loading-state of the art. Journal of Earthquake Engineering, 11, 46-88, https://doi.org/10.1080/13632460701280237

Ceresa, P., Petrini, L., \& Pinho, R. (2008). A fibre flexure-shear model for cyclic nonlinear behavior of RC structural elements. Research Report ROSE-2008/07. IUSS Press: Pavia, Italy.

Collins, M. P. (1978), Towards a rational theory for RC members in shear. ASCE Journal of Structural Division, 104(4), 649-666.

Collins, M. P., Vecchio, F. J., \& Mehlhorn, G. (1985). An international competition to predict the response of reinforced concrete panels. Canadian Journal of Civil Engineering, 12, 624-644. https://doi.org/10.1139/185-070

Elwood, K. J., \& Moehle, J. P. (2005). Axial Capacity Model for Shear-Damaged Columns. ACI Structural Journal, 102(4), 578-587. https://doi.org/10.14359/14562

EN 1998-3. (2005). Eurocode 8: Design of structures for earthquake resistance -Part 3: Assessment and retrofitting of buildings. European Committee for Standardization (CEN), Brussels.

Filippou, F. C., \& Constantinides, M. (2004). FEDEAS Lab - Getting Started Guide and Simulation Examples, NEESgrid Report 2004-22 and SEMM Report 2004-05. Retrieved from http://fedeaslab.berkeley.edu/

Filippou, F. C., \& Fenves, G. L. (2004). Methods of analysis for earthquake-resistant structures. In: Bozorgnia Y, Bertero VV (eds) Earthquake engineering: From engineering seismology to performance-based engineering. CRC Press, Boca Raton.

Hughes, T. J. R. (2000). The Finite Element Method: Linear Static and Dynamic Finite Element Analysis, Dover Publications.

Jean-Luc Chabert, ed. (1999) A History of Algorithms: From the Pebble to the Microchip, Berlin: Springer, pp. 86-91.

Lynn, A. C., Moehle, J. P., Mahin, S. A., \& Holmes, W. T. (1996). Seismic Evaluation of Existing Reinforced Concrete Columns. Earthquake Spectra, 12(4), 715-739. https://doi.org/10.1193/1.1585907

Megalooikonomou, K. G., Tastani, S. P., \& Pantazopoulou, S. J. (2018). Effect of Yield Penetration on Column Plastic Hinge Length. Engineering Structures Journal, Elsevier, 156, 161-174, https://doi.org/10.1016/j.engstruct.2017.11.003 
Sezen, H., \& Moehle, J. P. (2006). Seismic Tests of Concrete Columns with Light Transverse Reinforcement. ACI Structural Journal, 103(6), 842-849. https://doi.org/10.14359/18236

Tastani, S. P., \& Pantazopoulou, S. J. (2013). Reinforcement and concrete bond: State determination along the development length. ASCE J. of Structural Eng., 139(9), 1567-1581, Retrieved from https://ascelibrary.org/doi/10.1061/\%28ASCE\%29ST.1943-541X.0000725

Tastani, S. P., \& Pantazopoulou, S. J. (2013). Yield penetration in seismically loaded anchorages: effects on member deformation capacity. Techno press Earthquake and Structures, 5(5), 527-552, https://doi.org/10.12989/eas.2013.5.5.527

Vecchio, F. J., \& Collins, M. P. (1982). Response of Reinforced Concrete to In-Plane Shear and Normal Stresses, Publication No. 82-03, Department of Civil Engineering, University of Toronto, Canada.

Vecchio, F. J., \& Collins, M. P. (1986). The modified compression field theory for reinforced concrete elements subjected to shear. ACI Journal Proceedings, 83(2), 219-231.

Vecchio, F. J., \& Collins, M. P. (1988). Predicting the Response of Reinforced Concrete Beams Subjected to Shear Using Modified Compression Field Theory. ACI Structural Journal, 85(3), 258-268.

\section{Copyrights}

Copyright for this article is retained by the author(s), with first publication rights granted to the journal.

This is an open-access article distributed under the terms and conditions of the Creative Commons Attribution license (http://creativecommons.org/licenses/by/4.0/). 